\title{
KLouro: Um jogo educacional para motivar alunos iniciantes em programação
}

\author{
Max André de Azevêdo Silva ${ }^{1}$, Ayla Dantas², \\ ${ }^{1}$ Centro de Informática - Universidade Federal da Paraíba (UFPB) - \\ Campus I -João Pessoa, PB - Brasil. \\ ${ }^{2}$ Departamento de Ciências Exatas - Universidade Federal da Paraíba (UFPB) \\ Campus IV - Rio Tinto, PB - Brasil \\ $\{$ max.azevedo, ayla\} @dce.ufpb.br
}

\begin{abstract}
Considering that it is difficult for students of IT courses to understand and apply the concepts taught in introductory programming disciplines, it is necessary to investigate initiatives to help them overcome these difficulties and to motivate them to practice in different ways what they learn. This work presents the design of a Learning Object (LO) that follows a game interactive model which has been designed according to pedagogical and game design principles. This LO is called KLouro and is intended to make the students practice some introductory programming concepts.
\end{abstract}

Resumo. Com a evidente dificuldade que os alunos de cursos superiores de TI demostram ter em entender e aplicar os conceitos iniciais de programação, se faz necessário que haja iniciativas que busquem ajudá-los a superar essas dificuldades e motivá-los a praticar de diversas formas os conteúdos vistos.. Este trabalho apresenta o projeto de um Objeto de Aprendizagem (OA) que segue um modelo interativo de jogo, projetado de acordo com critérios pedagógicos e de Game design, Este OA se chama KLouro e tem como objetivo ajudar os alunos a praticarem de forma divertida alguns conteúdos introdutórios de programação.

\section{Introdução}

Segundo Deters et al. (2008), as disciplinas que envolvem o ensino de Algoritmos e Programação são consideradas desafiadoras pelos alunos, pois exigem 0 desenvolvimento de estratégias de resolução de problemas com base lógico-matemática. Muitos alunos têm dificuldades em entender e aplicar os conceitos lógicos mostrados em sala de aula. Segundo Martins, Mendes e Figueiredo (2010), parece existir um consenso entre professores e pesquisadores de que o aprendizado de programação não é uma atividade trivial, já que introduz no cotidiano do estudante uma série de requisitos cognitivos (como a capacidade de abstração e de resolução de problemas), além dos requisitos técnicos (como o domínio da linguagem de programação). Deters et al. (2008) afirma que a consequência disso é o elevado número de problemas de aprendizagem, favorecendo a ocorrência de reprovações e desistências em disciplinas introdutórias de programação.

Reprovações geram desmotivação nos alunos, prejudicando o processo de ensino-aprendizagem [Silva, Ivanda e Santos 2009]. Ao se desmotivarem, os alunos muitas vezes despertam uma aversão pela área de programação, fazendo com que cursar 
as disciplinas que envolvam conceitos de programação se torne uma tarefa árdua e desagradável. Essa dificuldade, em muitos casos, leva os alunos a desistirem da graduação mesmo que tenham interesse pela área. No trabalho de Silva, Ivanda e Santos (2009) se destaca que esse fato acarreta a falta de profissionais na área de tecnologia em geral, visto que dentre os alunos que ingressam no curso superior de Ciência da Computação, a minoria chega até a formação final.

Desse modo, é necessário que sejam providas maneiras alternativas de auxiliar os graduandos no processo de compreensão e aplicação dos conceitos de programação e algoritmos. Ibrahim et al. (2011) comenta que jogos educacionais podem oferecer muitos benefícios para o aprendizado dos estudantes com base na natureza altamente motivacional dos próprios jogos de computador, bem como por causa do comportamento da nova geração de alunos. Segundo Moratori (2003), o jogo pode ser considerado como um importante meio educacional, pois propicia um desenvolvimento integral e dinâmico nas áreas cognitiva, afetiva, linguística, social, moral e motora, além de contribuir para a construção da autonomia, criticidade, criatividade, responsabilidade e cooperação. Além disso, jogos de computadores promovem uma nova maneira de aprendizado para os estudantes, conforme sugerido por Prenski (2003). Com base nisso, acredita-se que a iniciativa de utilizar jogos educacionais pode ser uma maneira eficiente de auxiliar os alunos a ultrapassarem os obstáculos de aprendizagem inerentes à disciplina de Introdução à Programação de cursos superiores da área de Tecnologia da Informação (TI).

No processo de elaboração dos jogos é muito importante que sejam seguidos os princípios de game design [Crawford 1982]. Isso quer dizer que ao se pensar na criação de um jogo educacional, também é necessário pensar no seu design. Esse design se torna diferente do game design tradicional, pois como se trata de um jogo educacional, existe uma preocupação com todos os quesitos necessários para que seja um jogo, e também que se tenha uma base pedagógica e teorias de aprendizagem sendo aplicadas, visando auxiliar na aprendizagem do jogador. Existem muitos trabalhos que registram a utilização de jogos para o ensino de conceitos e lógica de programação, mas segundo Scaico et al. (2012), alguns desses jogos são frágeis em atender requisitos relacionados ao projeto instrucional, assim como os requisitos de game design. Partindo dessas premissas, este trabalho propõe o Objeto de Aprendizagem (OA) KLouro, do tipo jogo, cujo projeto foi desenvolvido com base nos conceitos de game-based learning [Prensky 2003] e apresenta o projeto desse OA e sua avaliação inicial considerando o protótipo que foi desenvolvido. Muitos artigos têm sido publicados sobre a aprendizagem através de jogos. Neste âmbito, existem iniciativas de aplicações que têm como função principal proporcionar um ambiente de contextualização da lógica de programação. Alguns exemplos são FurBot [Vahldick et al 2008], ProGame [Dantas et al. 2011] e Takkou [Barbosa; Fernandes; Campos 2011]. Os jogos citados possuem em comum a característica de serem voltados para o ensino de lógica e conceitos de programação em um nível mais avançado que apenas o de compreensão de algoritmos (foco do KLouro). Todavia, esses jogos são voltados apenas para plataforma desktop, o que impede que possam ser usados em dispositivos móveis, por exemplo, os quais vêm se tornando cada vez mais comuns. Em contraponto, o jogo KLouro foi projetado para rodar na Web, em dispositivos móveis (Android e iPhone) e em desktops (Windows e Mac OS) para que possa ser acessível por uma gama maior de usuários e seus dispositivos. Além disso, ele 
também foi projetado obedecendo aos princípios de game design e princípios pedagógicos e com um foco em conceitos introdutórios de programação em Python.

O restante deste artigo está organizado da seguinte forma. Na Seção 2 é apresentada a metodologia empregada neste trabalho. Na Seção 3 são apresentados a proposta do jogo KLouro, aspectos gerais do jogo, detalhes de cada fase e detalhes de implementação. A Seção 4 aborda a avaliação inicial do jogo em relação aos aspectos pedagógicos e técnicos. Por fim, a Seção 5 apresenta algumas conclusões e trabalhos futuros propostos.

\section{Metodologia}

Este trabalho consistiu inicialmente numa pesquisa bibliográfica para levantar critérios para avaliação técnica, pedagógica e de game design de objetos de aprendizagem. Posteriormente, deu-se início ao projeto e desenvolvimento do protótipo de um OA para apoiar o ensino introdutório de programação considerando os princípios propostos pela literatura. A seguir, foi realizada uma avaliação inicial do OA proposto observando os critérios de avaliação de Objetos de Aprendizagem seguindo abordagens comportamentalistas e construtivistas propostas por Reategui et al. (2010). Durante esta avaliação foi feita também uma análise da forma com que princípios de game design foram observados na concepção do jogo KLouro. Foi feito também um levantamento (survey) piloto em que de forma anônima, por meio de formulário online, alunos cursando a disciplina introdutória de programação puderam avaliar o protótipo do jogo.

\section{KLouro: Um Jogo educacional para motivar alunos iniciantes em programação}

O objetivo instrucional do jogo KLouro é ajudar o aluno a melhor compreender operadores lógicos e aritméticos da linguagem de programação Python e a analisar expressões lógicas em estruturas de controle de fluxo como "if", sendo portanto indicado para o início de uma disciplina introdutória de programação. O enredo do jogo conta a história de um rapaz que ingressa na universidade no curso de Ciência da Computação e que começa a aprender sobre lógica de programação. Porém, junto à felicidade de ser um "fera" no ensino superior, vem à sua cabeça a preocupação em relação a um costume no qual os alunos mais antigos do curso pregam uma "peça" nos alunos que estão ingressando no primeiro período (o "trote" universitário). Logo, chegado o dia em que os veteranos aplicariam o trote, alguns deles fazem uma proposta para que ele se livre do trote. Eles passariam algumas missões de ação que ele só conseguiria entender se estivesse dominando o básico de programação que estava aprendendo naquele momento na universidade. Se o rapaz conseguisse cumprir essas missões, estaria livre do trote. $\mathrm{O}$ detalhe é que as missões (condições para que passe de fase) são especificadas por meio de trechos de código. A cada fase, o nível de complexidade do jogo e da forma de expressar suas missões vai aumentando.

O jogador deve mostrar bastante atenção, raciocínio rápido e ao mesmo tempo deve entender bem qual é o objetivo de cada fase explicitado via algoritmo para que possa passar de fase. Cada fase apresenta novos elementos e quanto mais o jogador vai passando de fases mais aumenta a dificuldade da missão e a complexidade do algoritmo utilizado para especificá-la, na linguagem Python. A ideia do enredo é trazer alguns 
elementos da realidade do aluno iniciante em programação, mas ao mesmo tempo explorar a fantasia do jogador.

A introdução do jogo é composta por uma animação que demonstra todo o enredo, fazendo uma ligação entre a história e os objetivos principais do jogo. Ao iniciar cada fase, o jogador deverá entender qual é a missão que precisa ser cumprida para que passe para próxima fase. Na versão atual do protótipo para o KLouro, para descobrir qual é a missão (regra para passar de fase), o jogador deverá clicar no botão, em forma de exclamação, que será mostrado no canto superior direito da tela ou pressionar a tecla "espaço". Ao clicar no botão da tela ou pressionar a tecla, será exibida uma tela com a missão escrita em forma de Algoritmo, como mostra a Figura 1. Logo, para que o jogador entenda qual é missão da fase, ele deverá entender o código do algoritmo mostrado, pois só assim poderá jogar de forma que satisfaça às condições para que possa passar de fase. O cumprimento ou não da missão será testado após o temporizador, que se encontra na parte central superior da tela, chegar ao valor zero.

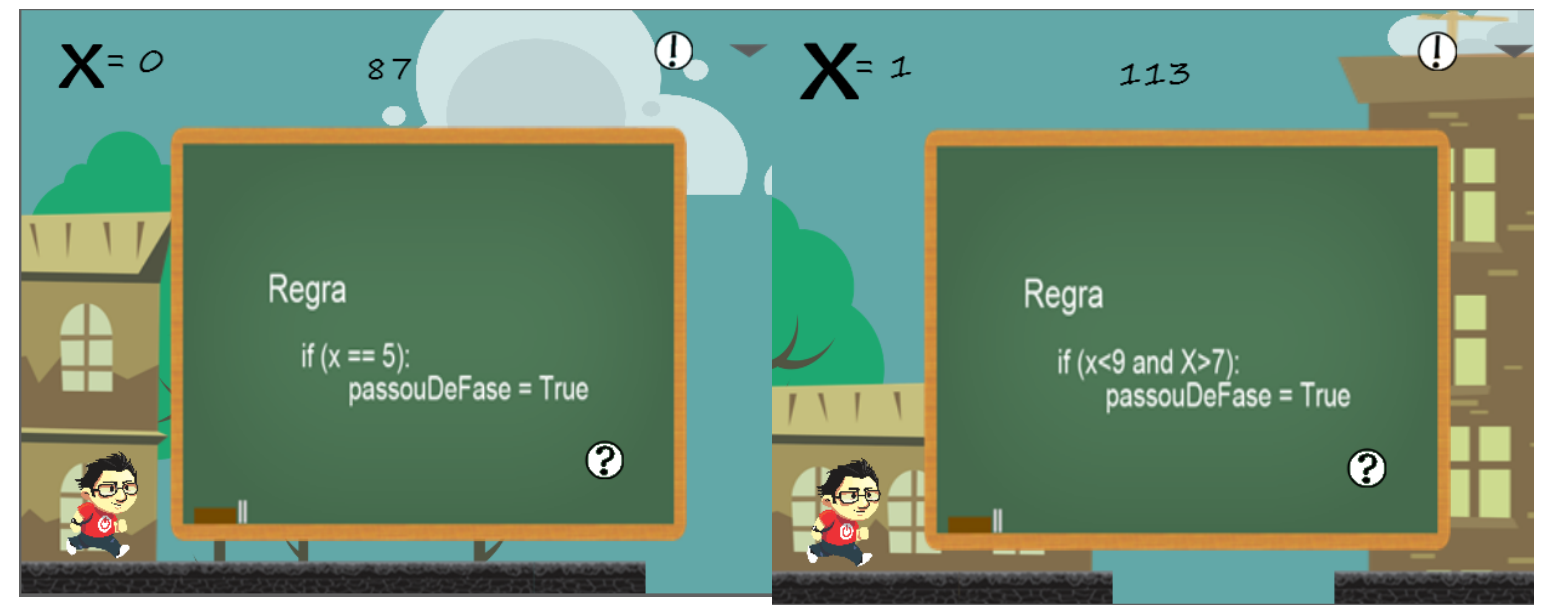

Figura 1 - Missões das Fases 1 (a) e 2 (b) do KLouro.

Na Figura 1a é mostrada a regra relativa à missão da primeira fase em forma de algoritmo, onde existe uma estrutura de decisão IF, que consiste em comparar se a variável "X" é igual a cinco (um trecho bem simples de código). O valor da variável chamada de "X" é exibido na tela principal do jogo (canto superior esquerdo). Sendo assim, o jogador sempre saberá o valor atual dessa variável. Para alterar o valor da variável, o jogador deve coletar alguns elementos existentes no cenário, que são os elementos "X+=1" e "X-=1". Existe um temporizador que determina em quanto tempo o jogador deve alterar o valor da variável " $X$ " de forma que atenda à condição do algoritmo da missão da fase, pois quando esse temporizador tiver o seu valor igual a zero, a regra relativa à missão será testada. Uma vez que a missão tenha sido cumprida, o jogador poderá seguir para a próxima fase. A Figura 1 b ilustra a missão utilizada na fase 2 do jogo.

Se tiver dúvidas sobre a missão, o jogador também tem a chance de obter mais informações. Na Figura 2 é mostrado um exemplo de um caso em que jogador não conseguiu interpretar o algoritmo, e acionou o botão de ajuda, que corresponde ao botão em forma de interrogação dentro de um círculo, ou pressionou a tecla $\mathrm{H}$ que corresponde ao atalho para ajuda (Help), e foi direcionado para a tela que exibe um texto explicativo sobre os elementos e a lógica usada no algoritmo que define a missão. Isso permite que o jogador possa aprender ou relembrar conceitos vistos em sala. 


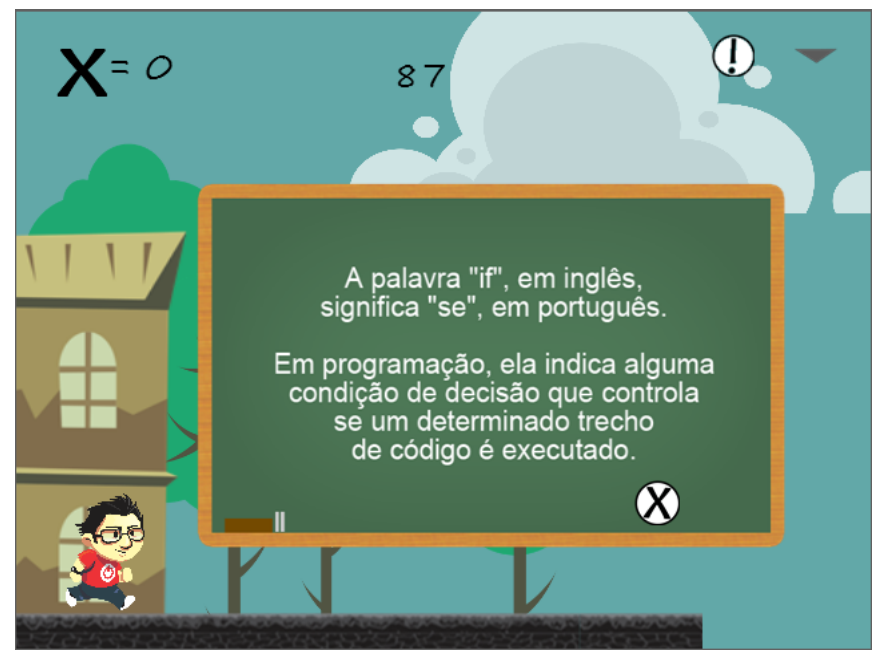

Figura 2 - Ajuda para entender o algoritmo da fase.

A Tabela 1 apresenta um resumo das características das fases até então projetadas e prototipadas para o jogo proposto neste trabalho. A tabela apresenta, de forma sintetizada, informações sobre Cenário, Desafios, Ações do Jogador, Conteúdo Trabalhado e Regras para a conclusão da Fase.

Tabela 1 - Resumo das fases.

\begin{tabular}{|c|c|c|c|c|c|}
\hline Fase & Cenário & Desafios & $\begin{array}{l}\text { Ações do } \\
\text { Jogador }\end{array}$ & $\begin{array}{c}\text { Conteúdo } \\
\text { Trabalhado }\end{array}$ & $\begin{array}{c}\text { Regras para } \\
\text { conclusão } \\
\text { da fase }\end{array}$ \\
\hline 1 & $\begin{array}{l}\text { O cenário dessa } \\
\text { fase é uma } \\
\text { universidade } \\
\text { imaginária com } \\
\text { prédios, } \\
\text { árvores, nuvens, } \\
\text { subidas, pisos } \\
\text { fixos, pisos } \\
\text { móveis, } \\
\text { buracos, } \\
\text { variável a ser } \\
\text { testada } \\
\text { elementos que } \\
\text { alteram o valor } \\
\text { da variável. }\end{array}$ & $\begin{array}{l}\text { Ultrapassar os } \\
\text { Elementos } \\
\text { buraco, degrau, } \\
\text { piso que cai e } \\
\text { piso móvel. O } \\
\text { jogador deverá } \\
\text { entender o } \\
\text { algoritmo que } \\
\text { expressa a } \\
\text { missão } \\
\text { composta pela } \\
\text { variável X, } \\
\text { estrutura de } \\
\text { decisão "if", o } \\
\text { operador } \\
\text { matemático == } \\
\text { e o literal } 5 . \\
\text { Para alterar o } \\
\text { valor } \\
\text { variável X será } \\
\text { necessário } \\
\text { ultrapassar } \\
\text { todos } \\
\text { obstáculos os }\end{array}$ & $\begin{array}{l}\text { Saltar os } \\
\text { obstáculos e } \\
\text { coletar os } \\
\text { elementos } \\
\text { X+=1 e X- } \\
=1 .\end{array}$ & $\begin{array}{l}\text { Estrutura de } \\
\text { decisão IF, } \\
\text { operadores } \\
+=\text { e -= e } \\
\text { igualdade } \\
(==) .\end{array}$ & $\begin{array}{l}\text { No momento } \\
\text { em que o } \\
\text { temporizador } \\
\text { tiver o seu } \\
\text { valor igual a } \\
0 \text { a variável } \\
\mathrm{X} \text { deve ter o } \\
\text { seu valor } \\
\text { igual a } 5 \text {. }\end{array}$ \\
\hline
\end{tabular}




\begin{tabular}{|c|c|c|c|c|c|}
\hline & & $\begin{array}{l}\text { coletar, antes } \\
\text { do } \\
\text { temporizador } \\
\text { chegar a } 0 \text {, os } \\
\text { elementos } \\
\text { " } x+=1 \text { " e " } \mathrm{x}- \\
=1 \text { ". }\end{array}$ & & & \\
\hline 2 & $\begin{array}{l}\text { O cenário dessa } \\
\text { fase é uma } \\
\text { universidade } \\
\text { imaginária com } \\
\text { prédios, } \\
\text { árvores, nuvens, } \\
\text { subidas, pisos } \\
\text { fixos, pisos } \\
\text { móveis, piso } \\
\text { acelerador } \\
\text { (novo na fase), } \\
\text { buracos, } \\
\text { variável a ser } \\
\text { testada } \\
\text { elementos que } \\
\text { alteram o valor } \\
\text { da variável. }\end{array}$ & $\begin{array}{l}\text { Além dos } \\
\text { mesmos } \\
\text { elementos da } \\
\text { fase 1, nessa } \\
\text { fase existe o } \\
\text { elemento "piso } \\
\text { acelerador'. O } \\
\text { algoritmo da } \\
\text { missão da fase } \\
\text { contém um } \\
\text { grau maior de } \\
\text { dificuldade, } \\
\text { pois esse é } \\
\text { composto pela } \\
\text { variável X, o } \\
\text { operador } \\
\text { lógico and e os } \\
\text { operadores > e } \\
<. \text { Para alterar } \\
\text { o valor da } \\
\text { variável X será } \\
\text { necessário } \\
\text { ultrapassar } \\
\text { todos } \\
\text { obstáculos os } \\
\text { coletar, antes } \\
\text { do } \\
\text { temporizador } \\
\text { chegar a } 0 \text {, os } \\
\text { elementos } \\
\text { "x+=1" e "x- } \\
=1 \text { ". }\end{array}$ & $\begin{array}{l}\text { Saltar os } \\
\text { obstáculos e } \\
\text { coletar os } \\
\text { elementos } \\
\text { X+=1 e X- } \\
=1 .\end{array}$ & $\begin{array}{l}\text { Estrutura de } \\
\text { decisão IF e } \\
\text { uso do } \\
\text { operador } \\
\text { lógico "and", } \\
\text { e dos } \\
\text { operadores } \\
>=<=\text {, ==, } \\
+=\mathrm{e}-=\text {. }\end{array}$ & $\begin{array}{l}\text { No momento } \\
\text { em que o } \\
\text { temporizador } \\
\text { tiver o seu } \\
\text { valor igual a } \\
\text { 0. A variável } \\
\text { X deve ter o } \\
\text { seu valor } \\
\text { entre } 6 \text { e } 9 \text {, } \\
\text { ou seja, } \\
\text { deverá ser } 7 \\
\text { ou } 8 \text {. }\end{array}$ \\
\hline
\end{tabular}

O protótipo inicial do Jogo Klouro está sendo desenvolvido utilizando o Construct2 [Scirra 2012]. O Construct 2 é um aplicativo que permite criar jogos para diferentes plataformas e para a Web sem que seja necessário codificar em linguagem de programação propriamente dita o jogo e onde vários elementos prontos são disponibilizados para a confecção do jogo. A ferramenta traz uma maneira de desenvolvimento orientada a eventos, ou seja, a cada elemento da tela se pode associar um conjunto de eventos. Além disso, o Construct2 contém vários plug-ins e comportamentos (behaviors) que possibilitam adicionar funcionalidades na ferramenta. 


\section{Avaliação}

Para a avaliação preliminar do Jogo Klouro foram observados os critérios de avaliação de Objetos de Aprendizagem seguindo abordagens comportamentalistas e construtivistas propostas por Reategui et al. (2010). Além disso, na avaliação que será apresentada nessa seção, se descreverá de que forma princípios de game design foram observados na concepção do jogo Klouro. Esta avaliação preliminar foi feia apenas pelos autores deste trabalho.

A Tabela 2 apresenta o resultado da análise da adequação do jogo KLouro considerando os aspectos pedagógicos propostos por Reategui et al. (2010).

Tabela 2 - Análise da adequação do jogo KLouro aos critérios pedagógicos propostos por Reategui et al. (2010)

\begin{tabular}{|l|l|}
\hline Questões & Perspectiva do jogo Klouro \\
\hline Apresenta informações em seções breves? & $\begin{array}{l}\text { As telas do jogo foram projetadas para } \\
\text { serem simples e objetivas, de modo que } \\
\text { rapidamente o jogador entenda os } \\
\text { comandos, regras, história e etc. }\end{array}$ \\
\hline $\begin{array}{l}\text { Fornece recompensa para respostas } \\
\text { corretas? }\end{array}$ & $\begin{array}{l}\text { Ao atingir seu objetivo explicitado no } \\
\text { código que define o desafio da fase } \\
\text { algoritmicamente, o jogador pode passar } \\
\text { para a próxima fase (recompensa). }\end{array}$ \\
\hline $\begin{array}{l}\text { Só permite seguir para outro nível se } \\
\text { obtiver resposta esperada do aprendiz? }\end{array}$ & $\begin{array}{l}\text { Se o jogador não conseguir cumprir a } \\
\text { missão de uma fase, esse deverá repetir a } \\
\text { fase até atingir seus objetivos. }\end{array}$ \\
\hline $\begin{array}{l}\text { Obriga o aluno, no caso de erros, a } \\
\text { retornar ao ponto anterior? }\end{array}$ & $\begin{array}{l}\text { O jogador poderá repetir quantas vezes } \\
\text { achar necessário a mesma fase. Além } \\
\text { disso, o jogo também possuirá a tela de } \\
\text { "menus de fases", onde esse poderá repetir } \\
\text { qualquer fase que esteja desbloqueada. }\end{array}$ \\
\hline $\begin{array}{l}\text { Propõe situações-problema que envolvam } \\
\text { a formulação de hipóteses, a investigação } \\
\text { e/ou a comparação? }\end{array}$ & $\begin{array}{l}\text { Com os elementos que são utilizados para } \\
\text { descrever as missões das fases, o jogador } \\
\text { tem como problema entender a missão e } \\
\text { descobrir como conseguirá atingi-la até o } \\
\text { temporizador em contagem regressiva } \\
\text { atingir 0. Dessa forma o jogador poderá } \\
\text { analisar o problema (missão) da fase, e } \\
\text { investigará quais elementos contidos no } \\
\text { jogo (como o X+=1 e X-=1) o ajudarão a } \\
\text { cumprir a missão da fase. }\end{array}$ \\
\hline $\begin{array}{l}\text { Apresenta recursos (como exercícios, } \\
\text { alternativas de navegação) que favorecem } \\
\text { a capacidade de elaboração a partir da } \\
\text { ação e reflexão? }\end{array}$ & $\begin{array}{l}\text { Em todas as fases do jogo existirá um } \\
\text { botão que tem por finalidade dar acesso a } \\
\text { uma tela que contém a missão em } \\
\text { algoritmo. Nela o jogador poderá acionar } \\
\text { outro botão que exibirá um texto } \\
\text { explicativo sobre os elementos utilizados } \\
\text { no algoritmo. }\end{array}$ \\
\hline
\end{tabular}


A Tabela 3 apresenta o resultado da análise da adequação do KLouro aos aspectos técnicos propostos também por Reategui et al. (2010).

Tabela 3 - Análise da adequação do jogo KLouro aos critérios técnicos propostos por Reategui et al. (2010)

\begin{tabular}{|c|c|}
\hline Questões & Perspectiva do jogo Klouro \\
\hline É isento de erros? & $\begin{array}{l}\text { Não existem erros conhecidos no jogo, } \\
\text { mesmo após sua utilização por alunos } \\
\text { iniciantes de programação. }\end{array}$ \\
\hline $\begin{array}{l}\text { O objeto de aprendizagem pode ser } \\
\text { utilizado em computadores com } \\
\text { configurações diversas, das mais simples } \\
\text { até as mais sofisticadas? }\end{array}$ & $\begin{array}{l}\text { O jogo está sendo desenvolvido com } \\
\text { gráficos 2D (duas dimensões), não } \\
\text { demandando, portanto, alto } \\
\text { processamento. Além disso, o uso de } \\
\text { Construct } 2 \text { permite que possa ser } \\
\text { exportado para diferentes plataformas } \\
\text { (incluindo tablets) e para a Web. }\end{array}$ \\
\hline $\begin{array}{llll}\text { O objeto pode } & \text { ser utilizado em } \\
\text { computadores } & \text { com } & \text { diferentes sistemas } \\
\text { operacionais } & \text { (ex. } & \text { Linux, Windows, } \\
\text { MacOS)? } & & \end{array}$ & $\begin{array}{l}\text { Por ser um jogo que também estará } \\
\text { disponível na Web, o KLouro pode ser } \\
\text { jogado em qualquer sistema operacional, } \\
\text { desde que o computador possua conexão } \\
\text { com a Internet. }\end{array}$ \\
\hline $\begin{array}{l}\text { As imagens são empregadas para ilustrar } \\
\text { conceitos e explicações ao invés de apenas } \\
\text { decorar as páginas? }\end{array}$ & $\begin{array}{l}\text { Todas as imagens que estão sendo } \\
\text { utilizadas no jogo têm sentido explicativo } \\
\text { ou significativo, tais como: botões, } \\
\text { animações, textos e etc... }\end{array}$ \\
\hline $\begin{array}{l}\text { O número de imagens apresentados em } \\
\text { cada página é adequado, considerando-se } \\
\text { que a presença excessiva de imagens pode } \\
\text { gerar sobrecarga cognitiva - terminando } \\
\text { por prejudicar os processos de } \\
\text { aprendizagem? }\end{array}$ & $\begin{array}{l}\text { As imagens que compõem as telas do jogo } \\
\text { foram projetadas de forma que haja noção } \\
\text { de espaço, dimensão e foco, tentando-se } \\
\text { não exagerar no número de imagens por } \\
\text { página. }\end{array}$ \\
\hline $\begin{array}{l}\text { Há contraste suficiente entre fontes e fundo } \\
\text { de tela, facilitando a leitura dos textos? }\end{array}$ & $\begin{array}{l}\text { Todos os textos estão sendo projetados de } \\
\text { forma que o jogador possa distinguir } \\
\text { facilmente os elementos textuais dos } \\
\text { demais elementos da tela. }\end{array}$ \\
\hline $\begin{array}{l}\text { As fontes utilizadas apresentam tamanho } \\
\text { adequado, ou permitem que sejam } \\
\text { aumentadas/diminuídas de acordo com a } \\
\text { necessidade de cada usuário? }\end{array}$ & $\begin{array}{l}\text { Na apresentação dos textos contidos no } \\
\text { jogo se está dando atenção à cor, fonte, } \\
\text { posição na tela e etc. Além disso, como o } \\
\text { jogo é disponibilizado na Web para } \\
\text { diferentes dispositivos, isso permite ao } \\
\text { jogador aumentar ou diminuir a tela como } \\
\text { desejar. }\end{array}$ \\
\hline $\begin{array}{l}\text { Os ícones que dão acesso a outras páginas } \\
\text { e funções do objeto são facilmente } \\
\text { compreensíveis? }\end{array}$ & $\begin{array}{l}\text { Os ícones utilizados no jogo foram } \\
\text { projetados para que sejam intuitivos. Por } \\
\text { exemplo, o botão de ajuda possui um } \\
\text { ícone de interrogação, o da missão possui } \\
\text { um ícone de exclamação, o de pular } \\
\text { animação possui um ícone de seta, e etc. }\end{array}$ \\
\hline
\end{tabular}




\begin{tabular}{|l|l|}
\hline $\begin{array}{l}\text { Os recursos interativos empregados vão } \\
\text { além da seleção de links e botões para } \\
\text { avançar ou recuar na apresentação dos } \\
\text { conteúdos? }\end{array}$ & $\begin{array}{l}\text { Além de botões de links e de controle de } \\
\text { telas, o jogador interage com o o } \\
\text { personagem principal. No caso da versão } \\
\text { do KLouro para computador, o jogador } \\
\text { interage com o personagem através das } \\
\text { setas do teclado. Já na versão para } \\
\text { dispositivos móveis, o jogador irá } \\
\text { interagir através da tela sensível ao toque } \\
\text { (touch screen). }\end{array}$ \\
\hline $\begin{array}{l}\text { O objeto de aprendizagem emprega } \\
\text { recursos gráficos que melhoram o aspecto } \\
\text { estético da interface, tornando mais } \\
\text { aprazível sua utilização? }\end{array}$ & $\begin{array}{l}\text { A interface gráfica do jogo Klouro está } \\
\text { sendo construída de forma que seja } \\
\text { atraente ao público-alvo, considerando } \\
\text { aspectos como senso estético, cores, } \\
\text { tamanhos e etc. }\end{array}$ \\
\hline
\end{tabular}

Além da análise dos aspectos pedagógicos e técnicos do jogo, foi feito também um levantamento piloto com alunos de uma turma de introdução à programação por meio de formulário online anônimo. Apenas três alunos participaram da pesquisa voluntariamente. Através desse levantamento inicial, os alunos foram questionados sobre a utilidade do jogo para lhes ajudar a entender operadores lógicos e todos concordaram que lhes ajudou. Perguntou-se também se sentiram vontade de jogar outra vez e se sugeririam o jogo a outros colegas e todos responderam que sim às duas perguntas. Quando perguntados sobre pontos positivos e negativos do jogo, observou-se que nenhum ponto negativo foi apontado e ao falar dos pontos positivos um dos alunos citou a capacidade do jogo de ensinar programação de uma forma divertida.

\section{Considerações Finais}

O principal objetivo deste trabalho foi apresentar uma nova proposta de um objeto de aprendizagem do tipo jogo, que tem como intuito principal motivar os alunos iniciantes em programação e praticar alguns conceitos bem introdutórios (como operadores e expressões lógicas). Acredita-se que projetá-lo já focando nos aspectos pedagógicos, técnicos e de game design que ele deveria ter foi bem positivo e que o objeto proposto neste trabalho atingirá o seu objetivo de forma eficaz.

Como trabalhos futuros, pretende-se finalizar a versão Web do jogo proposto, e assim testá-lo em ambiente de produção com alunos, já com outras fases além das duas fases descritas neste trabalho, em que se possa tratar de conteúdos como controles de fluxo com laços (while/for). Posteriormente pretende-se adaptá-lo também para a versão mobile e testá-lo nas plataformas Android e iOS e avaliar nas diversas plataformas a motivação dos alunos para utilizá-lo e sua percepção sobre a utilidade do jogo para melhor compreender alguns conteúdos introdutórios de programação.

\section{Referências}

Barbosa, L. S.; Fernandes, T. C. B; Campos, A. M. C. (2011) Takkou: Uma Ferramenta Proposta ao Ensino de Algoritmos. WEI - XIX Workshop sobre Educação em Computação, XXXI Congresso da Sociedade Brasileira de Computação. 
Crawford, C. The Art of Computer Game Design. (1982). http://wwwrohan.sdsu.edu/ stewart/cs583/ACGD_ArtComputerGameDesign_ChrisCrawford_1 982.pdf.

Dantas, V.; Freitas, P.; Alencar, L. (2011) ProGame: Um jogo para apoiar o ensino aprendizagem de programação. In: First Workshop on Applications to Provide Learning and Teaching Support (APPLETS), Aracaju - SE. Anais do XXII SBIE XVII WIE, 2011.

Deters, j. I.; Silva, j. M. C.; Miranda, e. M.; Fernandes, A. M. R. (2008) "Proposta de Diretrizes para Avaliação de Objetos de Aprendizagem Considerando Aspectos Pedagógicos e Técnicos”. XIX Simpósio Brasileiro de Informática na Educação. http://sbie2008.virtual.ufc.br/CD_ROM_COMPLETO/workshops/workshop\%202/O \%20Desafio\%20de\%20Trabalhar\%20com\%20Alunos\%20Repetentes\%20na.pdf.

Ibrahim, R.; Yusoff , R. C. M.; Mohamed, H.; Jaafar, A. (2011) Students Perceptions of Using Educational Games to Learn Introductory Programming. Published by Canadian Center of Science and Education, v.4, n.1, p. 205-216, Janeiro.

Martins, S. W.; Mendes, A. J.; Figueiredo, A. D. 2010. Comunidades de Investigação em Programação: Uma Estratégia de Apoio ao Aprendizado Inicial de Programação. IEEE-RITA (Revista Iberoamericana de Tecnologias de Aprendizagem), v.5, n.1, p. 39-46, Fevereiro.

Moratori, P, B. (2003). Por que utilizar jogos educativos no processo de ensino aprendizagem?. Rio de Janeiro, 33p. Tese de Mestrado (Mestrado de Informática aplicada à Educação), Universidade Federal do Rio de Janeiro.

Pietruchinski , M. H.; Neto, J. C.; Malucelli, A.; Reinehr, S. (2011). Os jogos educativos no contexto do SBIE: uma revisão sistemática de Literatura. Anais do XXII SBIE - XVII WIE.

Prensky, M. Digital game-based learning. (2003). New York: McGraw-Hill. Computers in Entertainment, v. 1, n. 1, Outubro.

Reategui, E.; Boff, E.; Finco, M. D. (2010) Proposta de Diretrizes para Avaliação de Objetos de Aprendizagem Considerando Aspectos Pedagógicos e Técnicos. CINTED-UFRGS Novas Tecnologias na Educação, v. 8 n. 3, dez.

Scaico, P; Marques, D. L; Melo, L. A; Azevedo, M. A; Neto, S.V.M; Oliveira, A; Júnior, J. A; Labanca, M; Scaico, A. (2012) Um jogo para o ensino de programação em Python baseado na taxonomia de Bloom. XXXII Congresso da Sociedade Brasileira de Computação. Disponível em: http://www.imago.ufpr.br/csbc2012/anais_csbc/eventos/wei/artigos/Um\%20jogo\%20 para $\% 20 \mathrm{o} \% 20$ ensino $\% 20 \mathrm{de} \% 20$ programacao $\% 20 \mathrm{em} \% 20$ Python $\% 20$ baseado $\% 20$ na $\% 20$ taxonomia\%20de\%20Bloom.pdf.

Silva, I. F. A.; Ivanda, M. M. S.; Santos, M, S. 2009. Análise de problemas e soluções aplicadas ao ensino de disciplinas introdutórias de programação. IX Jornada de Ensino, Pesquisa e Extensão - JEPEX. Disponível em: <http://www .eventosufrpe.com.br/jepex2009/cd/resumos/R1479-1.pdf>.

Vahldik, A.; Mattos, M. M; Hugo, M; Correa, C. H. Furbot, Ago. 2008. Disponível em: $<$ www.inf.furb.br/poo/furbot $>$. 